\title{
The New Nutrition Facts Label ${ }^{1}$
}

\author{
Samantha Buddemeyer and Gail P. A. Kauwell ${ }^{2}$
}

The Nutrition Facts label is a great tool for consumers who are trying to make better food choices. Whether you are interested in a product with less sugar or one with more fiber, the Nutrition Facts label can help you compare the nutrition content between similar foods. The original Nutrition Facts label was created in 1993 to help the public learn more about the nutritional value of the foods they were eating. The new Nutrition Facts label marks the first major change to the label in over 20 years. The only other change made to the label occurred in 2006 when the transfat content of foods was added (Center for Science in the Public Interest 2016). The new Nutrition Facts label design, released in May of 2016, was based on the latest scientific research connecting diet and chronic diseases (Marcason 2016). The changes made to the newest version of the Nutrition Facts label are shown in Figure 1. The updated information also came with an updated design aimed at making it easier for consumers to identify key information.

\section{New Nutrition Facts Label Features New Design Features}

The overall design of the new Nutrition Facts label is similar to the previous label, but with some improvements, as shown in Figures 1 and 2. For example, the font size for "servings per container," "serving size," and "calories" is larger, plus the serving size and calorie information is in bold font for emphasis. The line "calories from fat" was removed from the label (USFDA 2016). Studies have shown that the type of fat consumed is more relevant to health

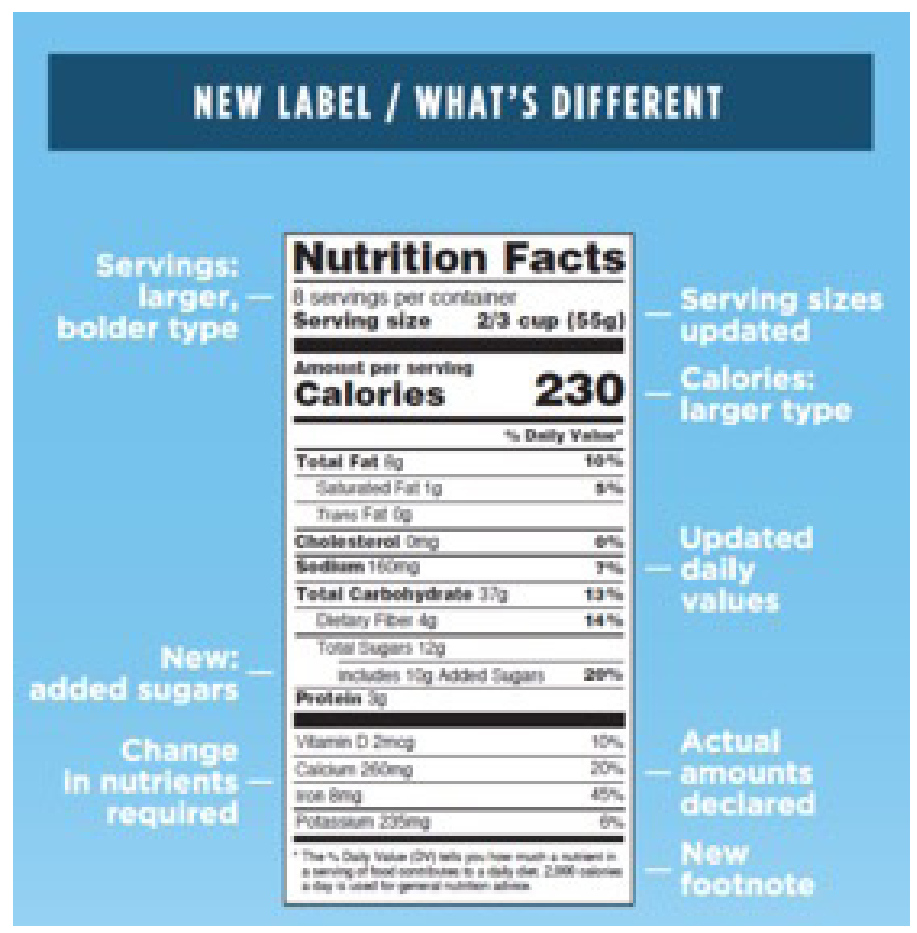

Figure 1. New Nutrition Facts label. Credits: USFDA (2016)

than the amount of fat consumed (Center for Science in the Public Interest 2016). For example, increasing trans fat intake is associated with an increased risk of heart disease. Additionally, replacing saturated fats with unsaturated fats is associated with lower total and LDL cholesterol, as well as a reduced risk of heart attacks and heart disease-related deaths (USDHHS and USDA 2015).

1. This document is FSHN17-5, one of a series of the Food Science and Human Nutrition Department, UF/IFAS Extension. Original publication date January 2018. Visit the EDIS website at http://edis.ifas.ufl.edu.

2. Samantha Buddemeyer, dietetic intern; Gail P. A. Kauwell, professor; Food Science and Human Nutrition Department; UF/IFAS Extension, Gainesville, FL 32611.

The Institute of Food and Agricultural Sciences (IFAS) is an Equal Opportunity Institution authorized to provide research, educational information and other services

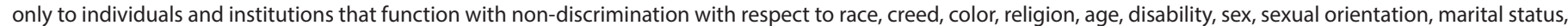

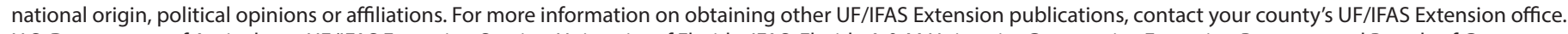
U.S. Department of Agriculture, UF/IFAS Extension Service, University of Florida, IFAS, Florida A \& M University Cooperative Extension Program, and Boards of County Commissioners Cooperating. Nick T. Place, dean for UF/IFAS Extension. 


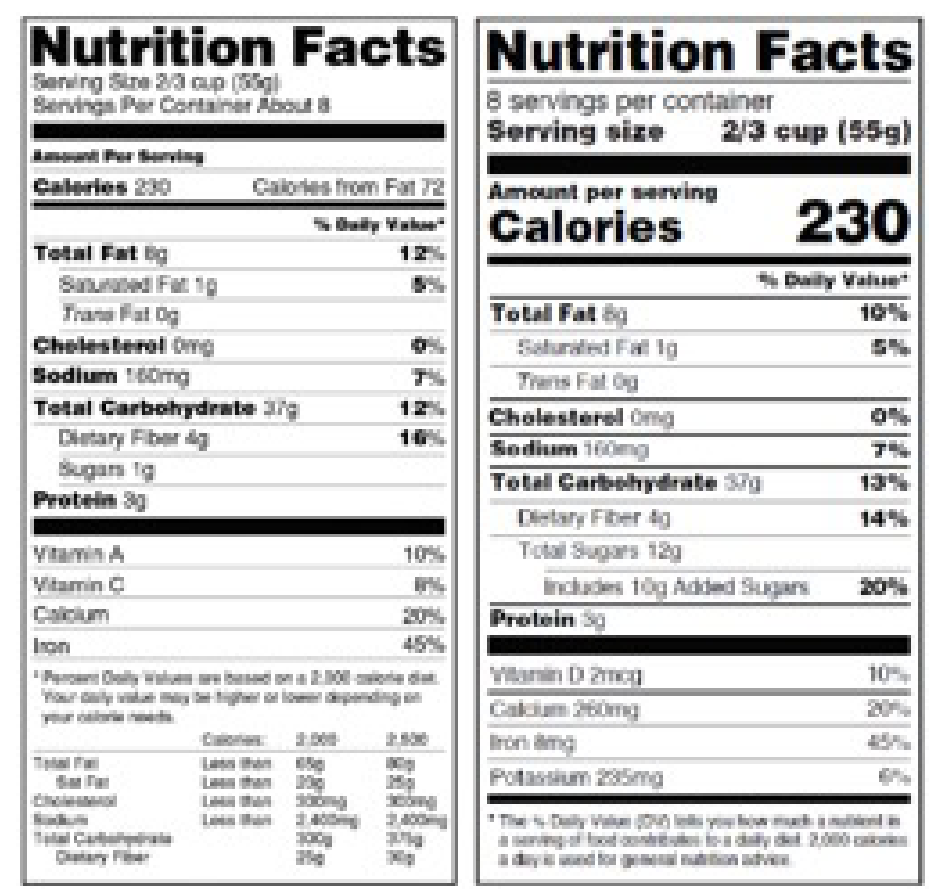

Figure 2. Comparison of the old and new food labels.

Credits: USFDA (2016)

If you ever wondered what "Daily Value" (DV) means, you are not alone. The new Nutrition Facts label defines the DV as the amount of each nutrient that goes toward your total intake for the day for one serving of that food. This amount is based on a 2,000 calorie diet (USFDA 2016). Comparing the DVs of foods you eat can help you make healthier food choices. When it comes to vitamins and minerals, the goal is to reach $100 \%$ of the DV. To help meet this goal, aim for foods with high DVs (20\% or more) for vitamins and minerals, but when it comes to sodium, added sugars, saturated fat, and trans fat, aim for low DVs (5\% or less) (Academy of Nutrition and Dietetics 2016).

\section{Added Features}

Vitamin D and the minerals potassium, calcium, and iron must be included on the new Nutrition Facts label, must show the specific amount of each nutrient per serving, and include the DV for each. Vitamin D and potassium, which are important for bone and heart health, respectively, are now replacing vitamins $A$ and $C$ on the Nutrition Facts label. Vitamin D and potassium are of importance for public health, and national surveys found that most of the population struggles to meet their need for these nutrients. Vitamins A and C are no longer required on the label because deficiencies of these vitamins are rarely seen, but manufacturers may include these or other nutrients on the label voluntarily. Calcium and iron, which are important for bone and red blood cell health, respectively, remain on the new label (USFDA 2016).
One of the biggest changes on the new Nutrition Facts label is the inclusion of information about "added sugars." The category of added sugars is defined as sugars added during processing or packaging (Center for Science in the Public Interest 2016). This information should help consumers identify foods that are natural sources of sugar, like fruit and milk, compared to those that have had extra sugar added (Center for Science in the Public Interest 2016). The grams of sugar per serving and the DV must be included on the label. The DV for added sugar is 50 grams, or about 12 teaspoons (Center for Science in the Public Interest 2016). Keep in mind that the goal is to limit your intake of added sugars. Consuming more than $10 \%$ of calories from added sugars makes it difficult to meet other nutrient needs while staying within your calorie needs (USFDA 2016).

\section{Updated Serving Sizes}

Over the years, the amount of food eaten at one sitting has increased due to changes in eating behaviors. As a result, the new Nutrition Facts label lists serving sizes that more closely match the amount of that food that people usually consume. For example, the serving size for soda has increased from 8 to 12 ounces, so the Nutrition Facts label will show nutrient values for 12 ounces. Foods that contain more than one but less than two servings will be labeled as containing one serving because people often consume the entire amount in one sitting. For example, a 20-ounce soda will be listed as one serving. These changes should make it easier for people to get a better idea of the calorie and nutrient intake they are likely to get from eating the foods they choose (USFDA 2016).

Two columns will be used on the new Nutrition Facts label for certain products that are larger than a single serving but could be eaten at one time. One column will show the amount of calories and nutrients "per serving" and the other "per package". For example, a 24-ounce soda would list the nutrition information for 12 ounces (one serving of the package) and 24 ounces (the entire package). Similarly, one pint of ice cream would list the nutrition information for 1 cup (one serving) and 1 pint (the entire package) (USFDA 2016).

The new Nutrition Facts label will start making its way onto food products soon, because most manufacturers must comply with new rules by July 26,2018 . Companies with less than $\$ 10$ million in annual food sales will have an extra year to comply (USFDA 2016). Once foods are labeled using the new format, it should be easier for consumers to make healthy food choices. 
Although the new Nutrition Facts label is designed to be easier to read and understand, education is still a huge part of making informed decisions. A good resource for learning how to read food labels is available on the Academy of Nutrition and Dietetics (the Academy) website (www. eatright.org). This resource provides a step-by-step guide to label reading. If you need a refresher, the Academy also provides a short summary video outlining the changes to the Nutrition Facts Label. If you still have questions, contact your local UF/IFAS Extension office and speak to the Family and Consumer Sciences agent.

\section{References}

Academy of Nutrition and Dietetics. 2016. "What does the new nutrition facts panel mean for you?" http://www. eatrightpro.org/resource/media/press-releases/new-infood-nutrition-and-health/new-nutrition-facts-panelacademy-explains. Accessed January 3, 2017.

Center for Science in the Public Interest. 2016. "New Nutrition Facts Labels to Feature Added Sugars, with Daily Value". https://cspinet.org/news/new-nutrition-facts-labelsfeature-added-sugars-daily-value-20160520. Accessed January 3, 2017.

Marcason, W. 2016. "New nutrition facts label”. Academy of Nutrition and Dietetics. https://www.eatrightpro.org/ resource/news-center/nutrition-trends/health-promotion/ what-are-the-proposed-new-food-labels. Accessed January $3,2017$.

US Department of Health and Human Services and US Department of Agriculture (USDHHS and USDA). 2015. "2015-2020 Dietary Guidelines for Americans. 8th Edition”. https://health.gov/dietaryguidelines/2015/guidelines/. Accessed May 30, 2017.

US Food and Drug Administration (USFDA). 2016. "Changes to the Nutrition Facts Label". http://www.fda. gov/Food/GuidanceRegulation/GuidanceDocumentsRegulatoryInformation/LabelingNutrition/ucm385663.htm. Accessed January 3, 2017. 